\title{
Students' Conceptions of Statistics: An Exploration of Attitudes across Majors
}

\author{
Hana Sulieman (Corresponding author) \\ Department of Mathematics \& Statistics \\ American University of Sharjah \\ Sharjah, UAE, 26666 \\ E-mail: hsulieman@aus.edu
}

Received: May 18, 2015 Accepted: July 24, 2015 Published: September 29, 2015

doi:10.5296/ire.v3i2.7622 URL: http://dx.doi.org/10.5296/ire.v3i2.7622

\begin{abstract}
Students from different majors taking statistics course view their statistics learning experience differently. In this work, a survey of 440 undergraduate students from various majors who took an introductory statistics course at the American University of Sharjah (AUS) in Fall 2012 or earlier semesters was conducted. Analysis of the survey data showed that $66 \%$ of the students have positive attitude toward statistics. Engineering majors who indicated the most negative attitude toward statistics associated their negativity to difficulty of the topic and the teaching method. Social sciences majors reported 'general dislike of mathematics' as the most significant contributing factor to their negative attitude toward statistics. Students with architecture and design majors were the most to associate their negative attitude toward statistics to its nonuse in their future career. On contrary, natural sciences' students were most likely to believe that statistics is an interesting topic and would be used in future career. Female students were also more likely than male students to find statistics related to their field of study and future career. Some implications of the findings for future teaching of statistics were discussed.
\end{abstract}

Keywords: statistics education, students' attitudes, statistics anxiety

\section{Introduction}

A course in statistics is required by large number of undergraduate majors as a major requirement or as a general education requirement. It is a common experience for statistics educators to observe some negative attitude of students in an introductory statistics class. 
This is obvious from the way the students react to the subject, the kind of questions they ask and the quality of the course work they deliver. Most students, particularly those in social science or education oriented majors, lack the understanding of the value of statistics to their field of study. Depending on the arrangement at a particular department, the statistics course can be taught by a departmental methodologist or by an instructor from the mathematics or/and statistics department. This inconsistency of who teaches the course can contribute to the attitudes that students develop toward statistics particularly those who lack sufficient mathematical skills.

Evidence of the students' view of a required statistics course as a formidable obstacle can be drawn from the titles of some of statistics references such as "Statistics without tears" (Rowntree, 1981) or some subtitles that read "Those of you who approach statistics with fear and foreboding ..." (Clegg, 1982, p. 9). Research has shown that students' attitudes toward statistics courses include anxiety, cynicism, fear and contempt (Hopkins et al., 1996). Onwuegbuzie (2004) found that as many as $80 \%$ of graduate students experience anxiety over learning statistics. Mills (2004) suggested that students' attitudes toward statistics may create a major obstacle for effective learning and hence teaching statistics and research methods courses become a major pedagogic challenge (Mulhern and Wylie, 2004). In a review of a number of studies regarding how students learn statistics, Garfield and Ben-Zvi (2007) suggested that teachers need to cultivate more positive beliefs about the value of statistics and statistical literacy. They also reported that teachers should also be aware that students come to statistics courses with a variety of perspectives regarding their own ability or lack of ability to succeed in the course.

Some factors are reported in the literature to be largely influential on students' attitudes toward statistics. These include level of statistics course (Waters et al., 1989), previous statistics experience, gender and grade-point average (Mills, 2004), age (Baloglu, 2003) and previous math experience (Zeidner, 1991; Schau, 2003). Mills (2004) reported that males were less likely than females to express fear of statistics and feel not confident mastering statistical material. They, however, scored lower than females on general interest in the subject and the degree of effort they were planning to expend on statistics. Baloglu (2003) showed that older students have more positive attitudes toward the usefulness of statistics but with higher level of statistics anxiety. Onwuegbuzie (2003) reported that students' attitudes, especially negative ones, can hinder or assist learning of statistics and can also influence directly their understanding of statistical concepts. They also can affect whether students will develop useful statistical thinking skills and apply statistics knowledge in their future professions. Schau (2003) found that students' attitudes toward statistics were positively related to their achievement in the subject.

There is limited amount of research comparing attitudes toward statistics across different disciplines or fields of study. The few existing studies in the literature have investigated attitudes within one discipline and recommended comparison across different ones. Slootmaeckers et. al. (2014) showed that among political science students, long-term retention of quantitative methods is negatively correlated with negative attitudes toward statistics and positively correlated with the perception of one's experience with statistics. In a 
study of 684 undergraduate students across business, criminal justice and psychology majors, Griffith et al. (2012) found that business majors were most positive and were more likely to believe statistics would be used in their future career. Within the business school, Mij (2009) reported that students with taxation major had more negative attitudes toward statistics than majors from accounting and marketing. Mathew and Aktan (2014) investigated attitudes toward statistics among undergraduate and graduate nursing students and compared them to non-nursing students. They found that nursing students scored less favorably toward statistics than non-nursing students. Pierce and Jameson (2008) compared students' attitudes toward statistics among education and computer science students and found that computer science students scored more positively on student attitudes subscales than education majors.

The primary objective of the present study is to reveal some patterns of attitudes toward statistics for students from different majors at the American University of Sharjah in United Arab Emirates and discuss some implications for teaching and curriculum development in statistics.

\section{Methodology}

\subsection{Context}

The American University of Sharjah (AUS), one of the premier institutions of higher education in the Middle East, was founded in 1997 as an independent and not-for-profit American style university in the Arabian Gulf. It serves nearly 6000 students of 92 nationalities.

As part of the general education requirements, the university offers four introductory Statistics courses taken by all students according to their degree majors. NGN111 (Introductory Statistics for Engineers) is required by all engineering majors and taught in the College of Engineering (CEN) by engineering faculty members; QBA201 (Quantitative Business Analysis) is required by all business and management majors and taught in the School of Business and Management (SBM) by business faculty members; STA201 (Introductory Statistics for Natural Sciences) is required by all sciences' majors and some majors from the College of Architecture and Design (CAD) and taught in the College of Arts and Sciences (CAS) by faculty members from the department of mathematics and statistics and STA202 (Introductory Statistics for Social Sciences) is required by all social sciences' majors in CAS and CAD and is also taught in CAS by faculty members from the department of mathematics and statistics.

\subsection{Participants}

In Fall2012, the department of mathematics and statistics conducted a campus-wide study to assess the level of interest among students to pursue further studies in statistics in a form of minor or major program in the field. A total of 440 undergraduate students participated in the study. All participants have completed an introductory level course in statistics prior to Fall 2012. The survey instrument included some items related to students' perception of their learning experience in the introductory statistics course and their attitudes toward the subject. Table 1 below presents the characteristics of the study participants. 
Table 1. Characteristics of the Participants

\begin{tabular}{llcc}
\hline \multicolumn{1}{c}{ Item } & \multicolumn{1}{c}{ Values } & $\boldsymbol{N}(\%)$ & Total \\
\hline Gender & Males & $165(37.5)$ & 440 \\
College & Females & $275(62.5)$ & \\
& Arts \& Sciences $($ CAS $)$ & $134(30.5)$ & 439 \\
& Architecture \& Design $($ CAD $)$ & $58(13.0)$ & \\
& Engineering $(C E N)$ & $142(32.5)$ & \\
Academic Standing & $105(24.0)$ & \\
& Business \& Management (SBM) & $42(10.0)$ & 438 \\
& Freshman & $196(45.0)$ & \\
& Sophomore & $110(25.0)$ & \\
\multirow{4}{*}{ complets course } & Junior & $90(20.0)$ & \\
& Senior & $145(33.0)$ & 439 \\
& NGN111: Intro Stats for Engineers & $96(22.0)$ & \\
& QBA 201: Quant. Bus Analysis & $52(12.0)$ & \\
& STA201: Intro Stats for Natural Scs & $139(32.0)$ & \\
& STA202: Intro Stats for Social Scs & $6(1.0)$ & \\
\hline
\end{tabular}

Of the 440 student participants, 145 (33\%) completed NGN111 (92\% of them from CEN), 96 (22\%) completed QBA201 (93\% of them from SBM), 52 (12\%) completed STA201 (69\% from CAS, 18\% from CAD) and 139 (32\%) completed STA202 (65\% from CAS, 32\% from CAD).

It should be pointed out that due to change of major, it is likely that the statistics course taken by a student does not belong to the school of the current major. Students who change majors across colleges are usually granted credit transfer for the statistics requirement. In addition students transferring from some approved regional or international institutions receive credit transfer for the statistics course completed (nearly $1 \%$ of the sample).

About one third of the sample is from CEN and an equal portion from CAS; nearly two thirds of the study participants were female students.

\subsection{Instrument and Procedure}

A questionnaire consisting of 13 items was developed for the study. The questionnaire focused on the Affect subscale measuring positive and negative feelings toward statistics and reasons behind such feelings. A negative feeling is expressed in the response "I hate to learn Statistics" whereas a positive feeling is expressed in the response "I do not hate to learn Statistics". The remaining items on the questionnaire allow students to express their thoughts on ways to improve the teaching of statistics to facilitate better learning of the subject (see the appendix for a copy of the questionnaire). The preliminary draft of the instrument was discussed in two brain-storming sessions that the author held with a group of 20 students who completed an introductory statistics course at AUS. The useful discussions in these sessions and some follow-up e-mail communications have helped crystalize the questionnaire items and tailor them in a way that suits the particular AUS educational experience. For example, in 
the meeting discussions, students explained that one of the reasons why students find statistics difficult in general is that contrary to Mathematics many concepts in Statistics cannot be visualized. Hence, this reason was added to the list of reasons why Statistics is hated, item 7.

Afterwards the author charged the students in her two sections of Mathematics for Business course to randomly distribute the questionnaire to AUS students who have already completed a course on introductory statistics. There were 44 students in the two sections, each student was asked to collect 10 surveys. The data collection task lasted for two weeks during the last quarter of Fall 2012 semester. Participants were assured that their responses were anonymous and their participation is voluntary.

Data were analyzed using the statistical software MINITAB 16. Binary logistic regression was used to identify factors that are associated with more positive attitude toward statistics. The binary response variable was defined by "Negative perception=1" and "Positive perception=2" with value 2 being the primary outcome of interest. Factors used in the model include: gender, college and academic standing. The factor representing course completed was not included in the analysis because of its confounding effect with college.

\section{Results}

Cronbach's alpha was calculated to measure the internal consistency of the negative attitude related items and the positive attitude related items. The alpha values were 0.871 for the negative attitude items and 0.659 for the positive attitude items. Due to the lack of sufficient variability in the responses on the positive attitudes items, the lower internal consistency (0.659) fails to meet the commonly used benchmark value of 0.7 .

Table 2 exhibits the results of the binary logistic regression attitude toward the learning of statistics classified by the college of the student.

Table 2. Binary logistic regression results

\begin{tabular}{cccc}
\hline Factor & Odds Ratio (OR) & 95\% C.I. for OR & p-value \\
\hline $\begin{array}{l}\text { Gender } \\
\text { Female }\end{array}$ & 1.34 & $1.12-3.83$ & 0.029 \\
College & & & \\
$\quad$ CAD & 3.23 & $1.39-7.47$ & 0.006 \\
CEN & 0.91 & $0.53-1.56$ & 0.737 \\
$\quad$ SBM & 0.76 & $0.44-1.33$ & 0.342 \\
Standing & & & \\
Sophomore & 0.82 & $0.40-1.67$ & 0.585 \\
$\quad$ Junior & 1.73 & $0.78-3.82$ & 0.177 \\
$\quad$ Senior & 1.06 & $0.48-2.33$ & 0.890 \\
Model & & 0.001 & \\
P-value & & & \\
\hline
\end{tabular}

Reference groups are Males for gender, CAS for college and freshman for standing. 
The model designates a reference value for each factor so as the likelihood of positive attitude in a particular group is compared to the same likelihood in the reference group using the Odds Ratio (OR). Male group is the designated reference group for gender, CAS for college and freshman for standing. If the OR is insignificantly different from 1 , then there is no significant difference in the likelihood of positive attitude between the reference group and the group compared to. If the OR is significantly different from 1, then the reference group and the group compared to have different likelihood (higher or lower) of positive attitude toward statistics. The $95 \%$ confidence interval for OR is also given in the table.

The p-values for gender and College of Architecture and Design (CAD) are less than 5\% indicating significant effects of these two factors on the likelihood of positive attitude toward statistics. For gender, the OR of 1.34 indicates that the female students are more likely to view their learning experience of statistics in a more positive fashion and express more positive attitude toward the subject than male students. The OR of 3.23 for CAD students reveals that CAD students are more likely to have positive attitude toward statistics than their counterpart in CAS. The p-values for the remaining factors in Table 2 are greater than $5 \%$ indicating insignificant effects. Further analysis of the data showed that $69 \%$ of female students reported positive attitude toward statistics as compared to $58 \%$ of male students. As for college, CAD students showed the highest rate of positive attitude among all colleges with only $13 \%$ of them reporting negative attitude.

Students were asked to provide reasons for their attitude. The given reasons were categorized into suitable number of categories and classified by the student's college and gender. Table 3 gives the reasons (categorized into 4 categories) for students who expressed positive attitude ( $66 \%$ of the sample) classified by their college.

Table 3. Reasons for positive attitude by college

\begin{tabular}{|c|c|c|c|c|c|}
\hline \multirow{2}{*}{$\begin{array}{l}\text { Positive Attitude } \\
\text { Category }\end{array}$} & $C A S$ & $C A D$ & $C E N$ & $S B M$ & \\
\hline & $\begin{array}{c}\text { Count } \\
\%\end{array}$ & $\begin{array}{c}\text { Count } \\
\%\end{array}$ & $\begin{array}{c}\text { Count } \\
\%\end{array}$ & $\begin{array}{c}\text { Count } \\
\%\end{array}$ & $\begin{array}{l}\text { Total } \\
\%\end{array}$ \\
\hline Easier Math & $\begin{array}{l}31 \\
37\end{array}$ & $\begin{array}{l}17 \\
35\end{array}$ & $\begin{array}{l}34 \\
42\end{array}$ & $\begin{array}{l}20 \\
34\end{array}$ & $\begin{array}{c}102 \\
38\end{array}$ \\
\hline Interesting topic & $\begin{array}{l}33 \\
39\end{array}$ & $\begin{array}{l}18 \\
38\end{array}$ & $\begin{array}{l}28 \\
34\end{array}$ & $\begin{array}{l}24 \\
41\end{array}$ & $\begin{array}{c}103 \\
38\end{array}$ \\
\hline Related to Major & $\begin{array}{l}14 \\
17\end{array}$ & $\begin{array}{c}8 \\
17\end{array}$ & $\begin{array}{c}9 \\
11\end{array}$ & $\begin{array}{l}11 \\
18\end{array}$ & $\begin{array}{l}42 \\
15\end{array}$ \\
\hline Use in future career & $\begin{array}{l}6 \\
7\end{array}$ & $\begin{array}{c}5 \\
10\end{array}$ & $\begin{array}{l}11 \\
13\end{array}$ & $\begin{array}{l}4 \\
7\end{array}$ & $\begin{array}{c}26 \\
9\end{array}$ \\
\hline Total & $\begin{array}{c}84 \\
100\end{array}$ & $\begin{array}{c}48 \\
100\end{array}$ & $\begin{array}{c}82 \\
100\end{array}$ & $\begin{array}{c}59 \\
100\end{array}$ & $\begin{array}{l}270 \\
100\end{array}$ \\
\hline
\end{tabular}


Nearly $75 \%$ of all students with positive attitude in each college find statistics both easier than mathematics and an interesting topic. CEN students are least likely to find statistics related to their major while they are most likely to believe statistics useful in their future career.

Table 4 presents the counts and percentages of the reasons for students with negative attitude (grouped into 5categories) across colleges.

Table 4. Reasons for negative attitude by college

\begin{tabular}{|c|c|c|c|c|c|}
\hline \multirow[t]{2}{*}{ Negative Attitude Category } & $C A S$ & $C A D$ & CEN & $S B M$ & \\
\hline & $\begin{array}{c}\text { Count } \\
\%\end{array}$ & $\begin{array}{c}\text { Count } \\
\%\end{array}$ & $\begin{array}{c}\text { Count } \\
\%\end{array}$ & $\begin{array}{c}\text { Count } \\
\%\end{array}$ & $\begin{array}{c}\text { Total } \\
\%\end{array}$ \\
\hline Dislike Math & $\begin{array}{l}29 \\
69\end{array}$ & $\begin{array}{c}3 \\
38\end{array}$ & $\begin{array}{c}7 \\
13\end{array}$ & $\begin{array}{l}16 \\
38\end{array}$ & $\begin{array}{l}55 \\
38\end{array}$ \\
\hline Difficulty & $\begin{array}{l}10 \\
24\end{array}$ & $\begin{array}{c}4 \\
50\end{array}$ & $\begin{array}{l}35 \\
67\end{array}$ & $\begin{array}{l}20 \\
48\end{array}$ & $\begin{array}{l}69 \\
48\end{array}$ \\
\hline Teaching Method/Professor & $\begin{array}{l}3 \\
7\end{array}$ & $\begin{array}{l}0 \\
0\end{array}$ & $\begin{array}{l}4 \\
8\end{array}$ & $\begin{array}{l}1 \\
2\end{array}$ & $\begin{array}{l}8 \\
6\end{array}$ \\
\hline Not related to Major & $\begin{array}{l}0 \\
0\end{array}$ & $\begin{array}{l}0 \\
0\end{array}$ & $\begin{array}{l}3 \\
6\end{array}$ & $\begin{array}{l}3 \\
7\end{array}$ & $\begin{array}{l}6 \\
4\end{array}$ \\
\hline Nonuse in future career & $\begin{array}{l}0 \\
0\end{array}$ & $\begin{array}{c}1 \\
12\end{array}$ & $\begin{array}{l}3 \\
6\end{array}$ & $\begin{array}{l}2 \\
5\end{array}$ & $\begin{array}{l}6 \\
4\end{array}$ \\
\hline Total & $\begin{array}{c}42 \\
100\end{array}$ & $\begin{array}{c}8 \\
100\end{array}$ & $\begin{array}{c}52 \\
100\end{array}$ & $\begin{array}{c}42 \\
100\end{array}$ & $\begin{array}{l}144 \\
100\end{array}$ \\
\hline
\end{tabular}

Difficulty of statistics and general dislike of mathematics appear to be the most prevalent reasons for the negative attitude toward statistics. As one might expect, students with majors in social sciences from CAS, CAD and SBM are most likely to hate statistics because they do not like mathematics in general. While engineering students are least likely (only 13\%) to hate statistics because of general dislike of mathematics, they are the most likely $(67 \%)$ to find the subject difficult. CAS students appear to be the least likely (24\%) to find statistics difficult and none of them think that statistics is not related to their major or it will not be used in their future career.

A closer look at Tables 3 and 4 shows that for all students who reported reasons for their attitudes, $86 \%$ of CAD students (48 out of 56) expressed positive attitude compared to $66 \%$ for CAS, $61 \%$ for CEN and $58 \%$ for SBM students. This result supports the findings of the binary logistic regression (Table 2) that showed that CAD students are more likely to express positive attitude toward statistics than students from other colleges.

In the following two tables: Tables 5 and 6 , we show the reasons for positive and negative attitudes, respectively, classified by student's gender. Table 5. Reasons for student with positive attitude by gender 


\begin{tabular}{lccc}
\hline $\begin{array}{l}\text { Positive Attitude } \\
\text { Category }\end{array}$ & $\begin{array}{c}\text { Males } \\
\text { Count } \\
\%\end{array}$ & $\begin{array}{c}\text { Females } \\
\text { Count } \\
\%\end{array}$ & $\begin{array}{c}\text { Total } \\
\%\end{array}$ \\
\hline Easier Math & 39 & 64 & 103 \\
& 40 & 36 & 38 \\
Interesting topic & 38 & 66 & 104 \\
& 39 & 37 & 38 \\
Related to Major & 12 & 30 & 42 \\
& 13 & 17 & 15 \\
Use in future career & 8 & 18 & 26 \\
& 8 & 10 & 9 \\
Total & 97 & 178 & 275 \\
& 100 & 100 & 100 \\
\hline
\end{tabular}

Table 5 clearly shows comparability of the two genders in terms of the reasons they expressed for their positive attitude toward statistics. Female students are slightly more likely than male students to find statistics related to their major and that it has use in future career.

Table 6. Reasons for students with negative attitude by gender

\begin{tabular}{lccc}
\hline Negative Attitude Category & Males & Females & \\
& Count & Count & Total \\
& $\%$ & $\%$ & 56 \\
\hline Dislike Math & 14 & 42 & 38 \\
Difficulty & 23 & 52 & 69 \\
& 35 & 34 & 48 \\
Teaching Method/Professor & 57 & 41 & 8 \\
& 4 & 4 & 6 \\
Not related to Major & 6 & 5 & 6 \\
Nonuse in future career & 5 & 0 & 4 \\
& 8 & 0 & 6 \\
Total & 4 & 2 & 4 \\
& 6 & 2 & 145 \\
& 62 & 82 & 100 \\
\hline
\end{tabular}

Significant differences can be seen between male and female students who have expressed negative views of statistics. Primarily, female students are more likely than males $(52 \%$ vs $23 \%$ ) to hate statistics because of their dislike of mathematics in general while male students are more likely than females ( $57 \%$ vs $41 \%$ ) to find statistics difficult. In addition, males aremore likely to view statistics as a subject that has no relation to their major of study nor does it have use in their future career. 
Tables 5 and 6 reveal that out of the 260 female students who reported reasons for their attitudes, 178 of them (69\%) expressed positive attitude. On the other hand, among the 159 male students, 97 of them (61\%) expressed positive attitude. This observation is in accordance with the results obtained from Table 2.

\section{Discussion}

The present study examined the responses of 440 undergraduate students from the American University of Sharjah to a survey about their learning experience of statistics and their perception of it. The study participants came from the four colleges: $30.5 \%$ from the College of Arts and Sciences (CAS), 13\% from the College of Architecture and Design (CAD), 32.5\% from the College of Engineering (CEN) and 24\% from the School of Business and Management (SBM) at the American university of Sharjah. Approximately $63 \%$ of the students were females and $37 \%$ males. They all had completed an introductory level course in statistics.

Approximately two-thirds of the surveyed students indicated positive attitude toward statistics. This finding is in accordance with prior findings (Mills, 2004; Waters et.al., 1989). Some statistically significant relationships were found among students' attitude toward statistics with CAD showing the highest level of positive attitude relative to students from other colleges. Additionally, female students expressed more positive attitude than their male counterparts.

For those students with positive attitude, "Easier Math" and "Interesting topic" are equally the most popular reasons across colleges and gender. Engineering students were least likely to make the connection between statistics and their majors although 13\% of them (highest rate) were able to draw the connection of how statistics may be used in their future career. Female students were more likely than male students to find statistics related to their majors and future careers.

For those students with negative attitude, social sciences' majors were more likely than other majors to view statistics negatively because of their "dislike of mathematics" in general. They join the statistics course with great level of math anxiety which for many of them is rooted since their schooling. Engineering students were the most likely to associate their negative attitude toward statistics to difficulty of the course and the teaching method. CAD students were the most to report "nonuse in future career" as a reason for their negativity toward statistics. As for student gender, female students reported that dislike of mathematics is the primary reason for their negative view of statistics. On the other hand, male students found no relation of the subject to their major of study or to their future career.

The results of this study can be used by teachers to improve students' attitudes toward statistics. Improving students' attitudes toward statistics has been shown to have direct positive effect on learning statistics. At the curriculum development level, introductory statistics courses should be integrated with other upper-level courses in the undergraduate curriculum not treated as "stand alone" courses. By having an isolated status of the introductory statistics courses, students do not perceive a connection between concepts learnt 
and their field of study or future career. Because a required statistics course is usually taken during freshman or sophomore year, later subject-specific courses at higher level can require students to do small research projects where quantitative methods are implemented. With this integrated curriculum, quantitative skills are reinforced, students' statistics anxiety is decreased and understanding of the value of statistics in the subject matter is increased.

At the course level, besides the need to teach the actual subject matter of statistics, teachers should provide appropriate interventions to help students overcome their negativity and anxiety toward statistics. It may be important to have repeated class discussions on why statistics should be learned and how it is relevant to students' chosen majors and future careers. It may also be useful to implement collaborative teaching of statistics courses where a department methodologist and an instructor from the mathematics and statistics department can co-teach the courses. For example, CAD students tend to believe that statistics has no use in their future careers. Although they represent the smallest portion of students who take STA201 and STA202, instructors of these two courses should sometimes present in the class application problems that are related to CAD majors. Data representing metrological site measurements and building geometry can be used to demonstrate some statistical concepts and offer useful interpretations. Here is one example of the comments some CAD students provided on the survey "Statistics is not related to some majors. Show students how statistics relates to their different disciplines".

CEN students attribute their negative attitude toward Statistics to difficulty of the subject. They also reported teaching method as another contributing factor. Difficulty in a subject can be caused by the teaching method. Engineering students take statistics in their school with engineering instructors teaching the course. Majority of these instructors have moderate exposure to statistics during their education which could be a reason for them not to deliver the subject in the best way to serve their students' learning as a statistician would. However, engineering instructors may be better to provide students with pertinent examples and applications that are specific to engineering field. The suggested collaborative teaching approach can be used here where a right balance between providing appropriate examples to explain concepts and teaching the subject matter in an efficient approach must carefully be considered. A CEN student reported "Professors should change the way they make students view statistics, since it is mostly shown as a formula / equation topic, instead of an interesting problem solving course. So instead of focusing on the equations, there should be more focus and attention to what these equations are used for".

Students with majors in social sciences in CAS and SBM reported dislike of Math and difficulty of the subject as the principle factors causing their negativity toward statistics. In general, these students suffer from poor mathematical training that leaves them unprepared for dealing with some abstract concepts and basic algebra. Instructors are required to use more effective teaching approaches that help these mathematically-challenged students overcome their fear and anxiety of mathematics in general. One way to do this is to start with actual numbers and then demonstrate the underlying formulas. Complicated symbols and notations must be avoided. Students must be given the opportunity to gain the mechanical skills in manipulating and analyzing data through doing exercises and course projects. From the 
author's long experience in teaching statistics to social sciences students, small research projects are efficient tools that help students gain immediate experience in collecting, analyzing and interpreting data and writing analysis report at the appropriate level to their education stage. An SBM student reported "Using more Statistics software would help more. More applications from real life such as projects in order to put lessons learnt in class to practice".

Although some useful findings were concluded from this study, there are some limitations that should be acknowledged. First, the study was done at the American University of Sharjah (AUS) only which could affect the generalizability of the findings although the participants in the study represented nearly all majors on campus. Second, the measurement instrument used in the study was designed locally to fit the particular context of AUS and capture relevant feedback about the four introductory statistics courses offered on campus. For better dissection of students' attitudes toward statistics, one could use well-known standardized assessments available on www.evaluationandstatistics.com (Bond, M. et al., 2012).

\section{Acknowledgment}

This research was completed for the Faculty Teaching Certificate Program offered by the faculty development center at the American University of Sharjah. The author wishes to acknowledge the support of the American University of Sharjah and express appreciation to Cindy Gunn, the director of the fcaulty development center, for her insightful suggestions throughout the planning and design of the project.

\section{References}

Baloglu, M. (2003). Individual differences in statistics anxiety among college students. Personality and Individual Differences, $34, \quad 855-865$. http://dx.doi.org/10.1016/S0191-8869(02)00076-4

Bond, M. E., Perkins, S., \& Ramirez, C. (2012). Students' perceptions of statistics: an exploration of attitudes conceptualizations, and content knowledge of statistics. Statistics Education Research Journal, 11(2), 6-25.

Clegg, F. (1982). Simple Statistics. Cambridge: Cambridge University Press.

Coetzee, S., \& Van der Merwe, P. (2010). “Industrial psychology students' attitudes towards statistics". SA Journal of Industrial Psychology, 36(1). http://dx.doi.org/10.4102/sajip.v36i1.843

Garfield, J., \& Ben-Zvi, D (2007). How students learn statistics revisited: A current review of research on teaching and learning statistics. International Statistical Review, 75(3), 372-396.

Griffith, J., Adams L., Gu, L., Hart, C., \& Nichols-Whitehead, P. (2012). Students' Attitudes Toward Statistics Across the Disciplines: a Mixed-Methods Approach. Statistics Education Research Journal, 11(2), 45-56.

Hopkins, K. D., Hopkins, B. R., \& Glass, G. V. (1996). Basic statistics for the behavioral sciences (3rd ed.). Needham Heights: Allyn and Bacon. 
Mathew, L., \& Aktan, N. M. (2014). Nursing Student Attitudes Toward Statistics. Journal of Nursing Education, 53(4), 233-237. http://dx.doi.org/10.3928/01484834-20140325-03

Mij, A. (2009). Differences in university students' attitudes and anxiety about statistics. Psychological Reports, 104(3), 737-744. http://dx.doi.org/10.2466/PR0.104.3.737-744

Mills, J. D. (2004). Students' attitudes toward statistics: Implications for the future. College Student Journal, 38, 349-361.

Mulhern, G., \& Wylie, J. (2004). Changing levels of numeracy and other core mathematical skills among psychology undergraduate between 1992 and 2002. British Journal of Psychology, 95, 355-370. http://dx.doi.org/10.1348/0007126041528176

Onwuegbuzie, A. J. (2004). Academic procrastination and statistics anxiety. Assessment and $\begin{array}{lllll}\text { Evaluation in Higher } & \text { Education, } & \text { 29(1), }\end{array}$ http://dx.doi.org/10.1080/0260293042000160384

Onwuegbuzie, A. J. (2003). Modeling statistics achievement among graduate students. Educ Psychol Meas, 63, 1020-1038. http://dx.doi.org/10.1177/0013164402250989

Pierce, R. L., \& Jameson, M. M. (2008). Students' attitudes toward statistics: Are there difference among various majors? Paper presented at the Joint Statistical Meetings 2008, Denver, CO.

Ridgeway, J., Nicholson, J., \& McCusker, S. (2007). Teaching statistics - Despite its $\begin{array}{llll}\text { applications. } & \text { Teaching } & \text { Statistics, } & \text { 29(2), }\end{array}$ http://dx.doi.org/10.1111/j.1467-9639.2007.00276.x

Rowntree, D. (1981). Statistics without tears. New York: Scribner.

Schau, C. (2003). Students' attitudes: The 'other' important outcome in statistics education. Joint Statistical Meetings, San Francisco. Retrieved June 24, 2009, from http://evaluationandstatistics.com/JSM2003.pdf

Slootmaeckers, K., Kerremans, B., \& Adriaensen, J. (2014). Too Afraid to Learn?! Attitudes Towards Statistics as a Barrier to Learning Statistics and to Acquiring Quantitative Skills. Politics, 34(2), 191-200. http://dx.doi.org/10.1111/1467-9256.12042

Waters, L. K., Martelli, T. A., Zakrajsek, T., \& Popovich, P. M. (1989). Measuring attitudes towards statistics in an introductory course on statistics. Psychological Reports, 48, 513-516. http://dx.doi.org/10.2466/pr0.1989.64.1.113

Yuhai, Z., Lei, S., Rui, W., Qinbo, Z., Chanjuan, L., Yongyong, X., \& Haixia, S. (2012). Attitudes toward statistics in medical postgraduates: measuring, evaluating and monitoring. BMC Medical Education, 12(117), 1-8.

Zeidner, M. (1991). Statistics and mathematics anxiety in social science students: Some interesting parallels. British Journal of Educational Psychology, 61(3), 319-328. http://dx.doi.org/10.1111/j.2044-8279.1991.tb00989.x 


\section{Appendix}

The objective of this survey is to investigate students' perception of their learning in Statistics courses at AUS and interest in pursuing major/minor in applied statistics. Taking few minutes to answer the questions carefully is greatly appreciated.
1. Gender:
1. Male
2. Female

2. College/School: 1. CAS

2. $\mathrm{CAAD}$

3. CEN

4. SBM

3. Academic Standing: 1. Freshman

2. Sophomore

3. Junior

4. Senior

4. Which Statistics course did you take or are taking at AUS:
1. NGN11
2. QBA201
3. STA201
4.
STA202

5. Other:

5. Semester of taking Stats course:

6. Statistics is a subject that:

1. I hate to learn

2. I do not hate to learn

3. I do not hate to learn but I know other students hate it

4. I hate to learn but I know other students like it

7. Statistics course is hated because: (check all that apply)

1. It contains a lot of Mathematics and many students hate Math

2. Many concepts in Statistics cannot be visualized and hence difficult to understand

3. It contains a lot of formulas

4. It is a word-problem based topic that requires a lot of logical thinking and reasoning

5. The way it is taught at AUS is not the right way

6. It does not help me in my studies at AUS

7. It does not help me in my future career

8. Other reasons:

8. Statistics course is NOT hated because: (check all that apply)

1. It is easier than other Math courses.

2. It is interesting topic with many real-life applications.

3. It helps me in my other courses at AUS

4. It helps me in my future career

5. Other reasons: 
9. In learning Statistics, I find using statistical computer package is :
O Very Important
O Important
O Not important
O No opinion

10. In learning Statistics, I find doing project (collect $\&$ analyze data through surveys or other ways):

Very Important $\bigcirc$ Important

$\bigcirc$ Not important

No opinion

11. In learning Statistics, I find problem-solving teaching approach and class discussion:
$\bigcirc$ Very Important $\bigcirc$ Important
O Not important

No opinion

12. Can you suggest to your professor other ways to improve Statistics learning at AUS:

13. If a major or a minor program becomes available at AUS, who do you think will be interested in taking it:
O You
Other Students
Do not know 


\section{Copyright Disclaimer}

Copyright reserved by the authors.

This article is an open-access article distributed under the terms and conditions of the Creative Commons Attribution license (http://creativecommons.org/licenses/by/3.0/). 